\title{
The role of diffusion-weighted imaging on 3 tesla magnetic resonance in the clinical staging and pathological grading of clear cell renal carcinoma
}

\author{
Hasan Gundogdu', Recep Bedir $^{2}$, Huseyin Eren ${ }^{3}$, Berrin Erok $^{4}$ \\ ${ }^{1}$ Department of Radiology, Recep Tayyip Erdogan University, Faculty of Medicine, İslampasa, Rize, Turkey \\ ${ }^{2}$ Department of Pathology, Recep Tayyip Erdogan University, Faculty of Medicine, İslampasa, Rize, Turkey \\ ${ }^{3}$ Department of Urology, Recep Tayyip Erdogan University Faculty of Medicine, İslampasa, Rize, Turkey \\ ${ }^{4}$ Department of Radiology, Health Sciences University, Okmeydanı Cemil Taşcı City Hospital, Istanbul, Turkey
}

\section{ABSTRACT}

Aim: To evaluate the contribution of the apparent diffusion coefficient (ADC) to distinguish between the four clinical stages and pathological grading in patients with clear cell renal cell carcinoma (RCC) on 3T MRI.

Methods: MRI of 93 patients with histopathological diagnosis of clear cell RCC were evaluated retrospectively. Clinical stage was evaluated according to American Joint Committee on Cancer and histopathological examination was evaluated according to the Fuhrman grading system. ADC values were compared for each clinical stage and pathological grade.

Results: Clinical stages were I in 51 patients (54.8\%), II in 14 patients (15\%), III in 15 patients (16.1\%), and IV in 13 patients (13.9\%). The Fuhrman grade of the patients were I in $8(8.6 \%)$ patients, II in $55(59.1 \%)$ patients, III in $23(24.7 \%)$ patients and IV in 7 (7.5\%) patients. Clinical stage I and Fuhrman grade I had significantly higher ADC values than all groups $(\mathrm{p}<0.001)$. The sensitivity was $81 \%$ and the specificity was $80.4 \%$ when the optimum cut-off value of ADC was taken as $1.41 \times 10^{-3} \mathrm{~mm}^{2} / \mathrm{s}$ to differentiate between clinical stage I and other stages (II, III, and IV) (AUC:0.910; 95CI:0.855-0.964; $p<0.001$ ). The optimum cutoff value of ADC was taken as $1.67 \times 10^{-3} \mathrm{~mm}^{2} / \mathrm{s}$ to differentiate between Fuhrman grade I and other grades (II, III and IV), the sensitivity was $88.2 \%$ and the specificity was $100 \%$ (AUC: 0.927 ; 95CI: $0.872-0.983 ; p<0.001$ ).

Conclusions: In patients with renal mass suggestive of clear cell RCC in imaging studies; The possibility of lymph node or distant metastatic lesion should be considered in patients with an ADC of the primary tumor site less than $1.41 \times 10^{-3} \mathrm{~mm}^{2} / \mathrm{s}$, and the presence of distant metastasis in patients with an ADC less than $1.22 \times 10^{-3} \mathrm{~mm}^{2} / \mathrm{s}$.

Key words: Clear cell renal cell carcinoma, apparent diffusion coefficients, clinical stage, Fuhrman grade, MRI

$\triangle$ Dr. Hasan Gundogdu

${ }^{I}$ Department of Radiology, Recep Tayyip Erdogan University, Faculty of Medicine, Íslampasa, Rize, Turkey

E-mail: hasan.gundogdu@erdogan.edu.tr

Received: 2021-12-09 / Revisions: 2021-12-20

Accepted: 2021-12-23 / Published online: 2022-01-01

\section{Introduction}

Renal cell carcinoma (RCC) is the most frequent malignant renal tumor with a prevalence of approximately $2 \%$ among adult cancers, accounting for about $80-90 \%$ of all parenchymal kidney tumors $[1,2]$. The age of presentation is typically 50-70 years, with a moderate male predilection of 2:1 [3]. Most clinical manifestations are nonspecific, and many patients are recognized incidentally in earlier stages on imaging studies performed for other reasons. The classic triad of hematuria, 
flank pain, and mass is seen in only $10 \%$ of patients with advanced tumors [4].

RCC represents a heterogeneous group of tumors with many different histological varieties. Clear cell, papillary, and chromophobe RCCs constitute the three main histological subtypes with the malignant course, of which $\sim 75 \%$ are the clear cell subtype in the adult population $[5,6]$. The prognosis of $\mathrm{RCC}$ is closely related to the pathological subtypes. Clear cell RCC originates from the proximal tubule epithelium and is the most common and malignant subtype of RCCs. The five-year cancer-related survival rate is the lowest compared to other subtypes at $68.9 \%$ [7-8]. These main pathological subtypes of RCC can often be noninvasively differentiated by imaging characteristics [9]. Clear cell RCC has a more heterogeneous appearance due to multiple areas of hemorrhage, internal necrosis, and cystic changes, in addition to a tremendous amount of enhancement.

At the microscopic evaluation, clear cell RCCs are characterized with tumor cells having clear cytoplasm due to the accumulation of glycogen and lipids accompanying in varying proportions to the cells with granular eosinophilic cytoplasm [4]. Diffusion-weighted imaging (DWI), a magnetic resonance (MR) imaging technique based on the molecular mobility of water molecules, demonstrates high signal intensity in the lesions with dense cellularity and weak interstitium that limit the mobility of water molecules, as in tumoral processes. The apparent diffusion coefficient (ADC) is a parameter that allows the quantification of restricted diffusion. It is used as an indicator of cell proliferative activity and provides insight into the nature of the lesions in various parts of the body $[10,11]$. DWI is a valuable tool in detecting metastatic lymph nodes and differentiating high-grade tumors from lowgrade ones [12-14].

Various studies have shown that ADC is significantly different between clear-cell RCC and non-clear-cell RCC subtypes [9, 15,16]. Recently, the utility of ADC has been suggested in predicting the clinical stage of clear cell RCC $[17,18]$. However, studies reporting the relationship between $\mathrm{ADC}$ and the clinical stage of clear cell RCC are few in the literature, and most of them were performed on 1.5 Tesla (T) MR imaging [18]. Our study aims to investigate the utility of DWI with ADC measurement on 3T MR imaging in clinical staging and pathological grading of clear cell RCCs.

\section{Materials and methods}

The study was approved by the Recep Tayyip Erdoğan University Faculty of Medicine Clinical Research Ethics Committee (Date: 2021-11-11/No:2021/195). All the procedures were carried out in accordance with ethical rules and the principles of the Declaration of Helsinki. Due to the design of our study, an informed consent form could not be obtained from the patients. Demographic characteristics, medical history, surgical notes, and pathology results of all patients, in whom 3T MR imaging was performed for the evaluation of the kidney masses with pathological diagnosis of clear cell RCC made by examining the tissues obtained in radical/partial nephrectomy between February 2016 and September 2021 were retrospectively analyzed from the hospital information system. Patients under 18, patients who had MR imaging or nephrectomy surgery in another center, patients who underwent MR imaging with $1.5 \mathrm{~T}$ MR device, patients with poor MR imaging quality, and patients whose medical information could not be reached were excluded from the study. 


\section{MR Imaging}

MR imaging was performed with the patient in the supine position, using a $3 \mathrm{~T}$ MR scanner (Discovery w750, GE Healthcare, United States). Antecubital intravenous access was established before the examination, and a bolus injection of contrast material was administered intravenously, following the precontrast images. Conventional, dynamic, and DWI were obtained using standard abdominal coils. For all patients, axial and coronal section T2-weighted (T2w) single-shot fast spin-echo (FSE) sequences, axial section T1-weighted (T1w) dual-echo in-phase and out-of-phase sequences, diffusion-weighted images were taken before contrast agent injection. Diffusion-weighted images were obtained by applying diffusionsensitizing gradients with different $b$ values (50 $\left.\mathrm{sec} / \mathrm{mm}^{2}, 800 \mathrm{sec} / \mathrm{mm}^{2}\right)$ in all three directions $(\mathrm{x}, \mathrm{y}, \mathrm{z})$ to the echo-planar SE T2w sequence in the axial plane. For each b-value, isotropic diffusion-weighted images that eliminate directional signal flares were generated. ADC maps were generated automatically by the instrument using each cross-sectional image.
After diffusion-weighted images were obtained, the gadolinium contrast agent was administered intravenously at a dose of 0.1 $\mathrm{mmol} / \mathrm{kg}$ with an automatic injector at a rate of $3 \mathrm{ml} / \mathrm{sec}$ through the vascular access established before the examination, and highresolution T1w fat-suppressed TSE axial and coronal section images were obtained (Table 1). For the evaluation of kidneys, all sequences were obtained at breath-holding. After the images were obtained, they were recorded in our hospital's PACS (Picture Archiving and Communication System).

\section{Image analysis}

Imaging data for each of the 93 renal masses were evaluated prior to reviewing the pathological data by a single reviewer (H.G) with 7 years of experience. The ADC was manually calculated by setting a region of interest (ROI) within the tumor using a workstation. ROIs were placed in a single location within the solid components of the tumor based on visual evaluation, which was seen as the brightest on DWI and the darkest on ADC maps, avoiding areas of necrosis, cystic

Table 1. Parameters for MR imaging.

\begin{tabular}{|l|l|l|l|l|l|}
\hline Parameters & $\begin{array}{l}\text { Axial T2W } \\
\text { imaging }\end{array}$ & $\begin{array}{l}\text { Coronal T2W } \\
\text { imaging }\end{array}$ & $\begin{array}{l}\text { In-phase/out of } \\
\text { phase imaging }\end{array}$ & CE MRI & DWI \\
\hline Echo time (m) & 84 & 84 & $2.4 / 5.6$ & 1.5 & 56 \\
\hline Repetition time (ms) & 3768 & 3000 & 230 & 3.5 & 2700 \\
\hline Flip angle (degrees) & 90 & 90 & 90 & 15 & 90 \\
\hline Intersection gap (mm) & 1 & 1 & 1 & -2.5 & 1 \\
\hline Section thickness (mm) & 5 & 5 & $5-6$ & 5 & $5-6$ \\
\hline Field of view (mm) & $360-400$ & $360-400$ & $360-400$ & $340-400$ & $360-400$ \\
\hline Matrix & $320 \times 224$ & $288 \times 192$ & $256 \times 192$ & $288 \times 224$ & $128 \times 128$ \\
\hline $\begin{array}{l}\text { Parallel imaging } \\
\text { acceleration factor }\end{array}$ & 2 & - & 2 & 2 & 2 \\
\hline
\end{tabular}

MR: Magnetic resonance, DWI: Diffusion-weighted imaging, CE MRI: Contrast-enhanced magnetic resonance imaging. 
degeneration, and hemorrhage that typically show no enhancement on dynamic contrastenhanced MR images. The ROI was set in an as large area as possible with the ROI size between 90-110 $\mathrm{mm}^{2}$ (mean ROI area; $98 \mathrm{~mm}^{2}$ ). The ADC value from a single ROI was accepted as the representative ADC of the renal lesion and expressed as mean \pm standard deviation in the

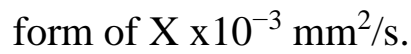

\section{Clinical staging}

The clinical stage was determined and recorded according to the 2010 TNM classification of the American Joint Committee on Cancer (AJCC) [19]. The relationship between DWI findings and the clinical stages of the patients was investigated.

\section{Pathological analysis}

A nuclear grade for each tumor using the Fuhrman nuclear grading system, the most widely used histopathological grading system defined by Furhman et al. [20], was assigned, unaware of MR imaging findings. In the Fuhrman classification, a grade is given to the tumors between grade I-IV; grade I indicates the best prognosis and grade IV the worst (Table 2).

Table 2. Fuhrman grading system.

\begin{tabular}{|l|l|}
\hline Grade & Fuhrman nuclear grading \\
\hline Grade 1 & $\begin{array}{l}\text { Nucleoli are absent or } \\
\text { inconspicuous and basophilic at } \\
\text { 400x }\end{array}$ \\
\hline Grade 2 & $\begin{array}{l}\text { Nucleoli are conspicuous and } \\
\text { eosonophilic at 400x and visible } \\
\text { but not prominent at 100x }\end{array}$ \\
\hline Grade 3 & $\begin{array}{l}\text { Nucleoli are conspicuous and } \\
\text { eosonophilic at 100x }\end{array}$ \\
\hline Grade 4 & $\begin{array}{l}\text { Extreme nuclear } \\
\text { pleomorphisim,multinucleate } \\
\text { giant cell and /or rhabdoid } \\
\text { sarcomatoid differentiation }\end{array}$ \\
\hline
\end{tabular}

In 3 patients with renal masses in both kidneys, clinical staging and Fuhrman grading were performed based on the tumor of the larger size.

\section{Statistical Analysis}

Statistical analyses were performed using the IBM SPSS Statistics, Version 23.0 (SPSS Inc., Chicago, USA) program. Descriptive statistics of both groups were reported as frequency and percentages within the groups (n, \%). Continuous numerical variables were analyzed by normality analyses. Accordingly, those with normal distribution were reported as mean \pm standard deviation, and those without normal distribution were reported as median (minmax). Difference analyzes between groups were performed with Student's t-test or MannWhitney U test. The distribution of categorical data between the groups was evaluated with the Chi-square test. Relationships between parameters were evaluated with Spearman correlation analysis and reported with rho coefficient. ROC curve analyzes were performed to evaluate the parameters' clinical stage and pathological grading performances and determine the appropriate threshold values. Accordingly, area under curve (AUC), sensitivity and specificity values were reported. A $p$-value $<0.05$ was considered statistically significant.

\section{Results}

164 patients who underwent nephrectomy for RCC were retrospectively evaluated. 29 patients diagnosed with non-clear cell RCC were excluded. After that, 35 patients who did not have preoperative MR imaging or had MR imaging but at $1.5 \mathrm{~T}$ MR Device were also excluded. Lastly, 7 patients were excluded due to the poor quality of DWI (Figure 1).

The remaining 93 cases, of whom $73(\% 78,5)$ were male, and $20(\% 21,5)$ were female, with a mean age of $60,25 \pm 11,65(39-77)$, were 


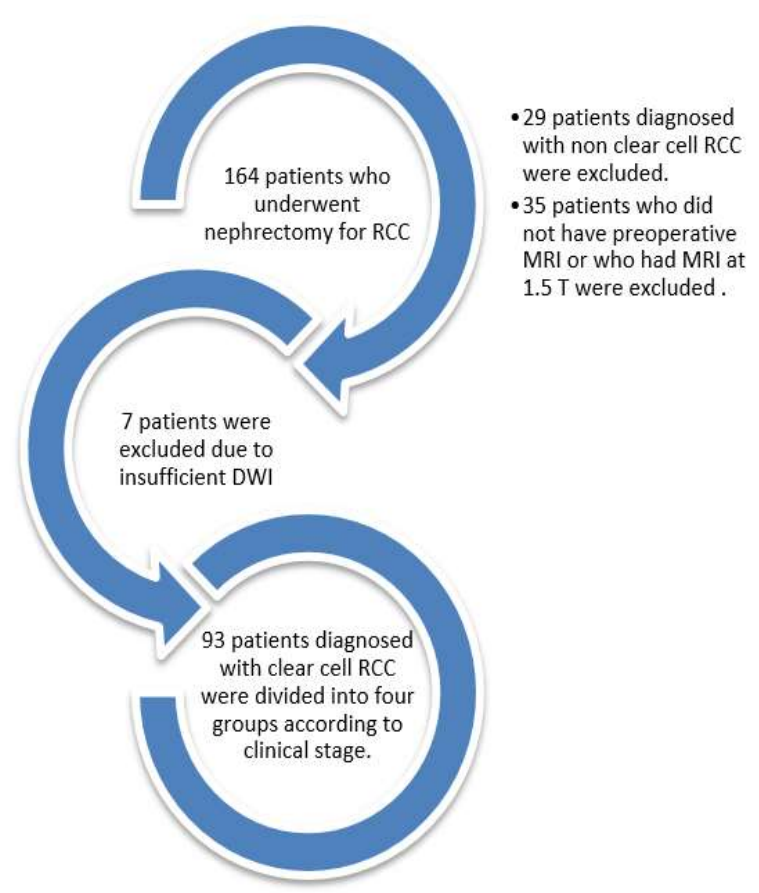

Figure 1. Flowchart for patient selection.

recruited for the study. Left (54.8\%) nephrectomy was performed in $51(45.2 \%)$ patients, and right nephrectomy was performed in 42 (\% 45.2) patients. Partial nephrectomy was performed in 27 (29\%) patients and radical nephrectomy in $66(71 \%)$ patients. According to clinical stages and Fuhrman grades, these 93 cases were divided into four groups according to clinical stages.

Clinical stages were I in 51 patients (54.8\%), II in 14 patients (15\%), III in 15 patients $(16.1 \%)$, and IV in 13 patients (13.9\%). The Fuhrman grade of the patients were I in $8(8.6 \%)$ patients, II in $55(59.1 \%)$ patients, III in $23(24.7 \%)$ patients, and IV in $7(7.5 \%)$ patients. There was a moderate positive correlation between clinical stage and Fuhrman grade $($ rho $=0.618$; $p<0.001)$. For all 93 patients, the median ADC of clear cell RCC was $1.42 \times 10^{-3} \mathrm{~mm} 2 / \mathrm{sec}$ (min-max: $0.97-1.86 \times 10^{-3} \mathrm{~mm}^{2} / \mathrm{s}$ ).

The mean ADC value for stage I was $1.59 \pm 0.18 \times 10^{-3} \mathrm{~mm}^{2} / \mathrm{s}$, for stage $\geq$ II was $1.23 \pm 0.18 \times 10^{-3} \mathrm{~mm}^{2} / \mathrm{s}$, for stage $\geq$ III was
$1.15 \pm 0.14 \times 10^{-3} \mathrm{~mm}^{2} / \mathrm{s}$ and for stage IV was $1.07 \pm 0.64 \times 10^{-3} \mathrm{~mm}^{2} / \mathrm{s}$. Stage I had significantly higher ADC values than all groups $(p<0.001)$ (Figure 2). ADC values for each stage are given in table 3 .

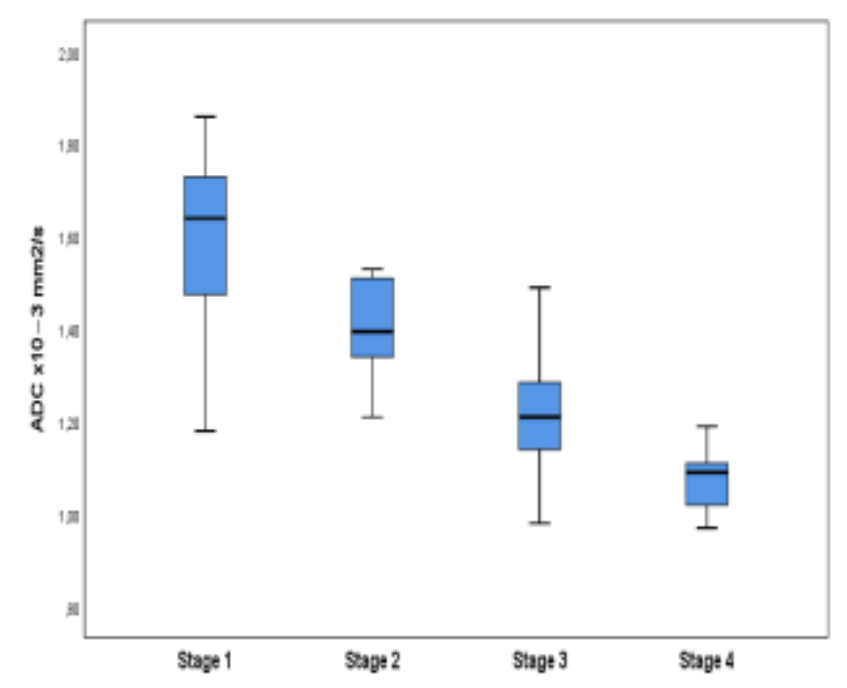

Figure 2. The box plot of ADC values in clinical stages.

Table 3. ADC values according to clinical stage and pathological grades of clear cell RCCs.

\begin{tabular}{|l|c|c|c|c|c|}
\hline \multirow{2}{*}{ Parameters } & \multicolumn{4}{|c|}{ ADC $\mathbf{x 1 0}^{-3} \mathbf{~ m m}^{2} / \mathbf{s}$} \\
\cline { 2 - 6 } & & Mean & SD & Min & Max \\
\hline \multirow{4}{*}{ Clinical stage } & $\mathbf{1}$ & 1.59 & 0.18 & 1.18 & 1.86 \\
\cline { 2 - 6 } & $\mathbf{2}$ & 1.40 & 0.10 & 1.21 & 1.53 \\
\cline { 2 - 6 } & $\mathbf{3}$ & 1.22 & 0.16 & 0.98 & 1.49 \\
& $\mathbf{4}$ & 1.07 & 0.06 & 0.97 & 1.19 \\
\hline \multirow{4}{*}{$\begin{array}{l}\text { Fuhrman } \\
\text { grade }\end{array}$} & $\mathbf{1}$ & 1.76 & 0.07 & 1.68 & 1.85 \\
\cline { 2 - 6 } & $\mathbf{2}$ & 1.52 & 0.18 & 1.13 & 1.86 \\
\cline { 2 - 6 } & $\mathbf{3}$ & 1.17 & 0.14 & 0.97 & 1.48 \\
\cline { 2 - 6 } & $\mathbf{4}$ & 1.19 & 0.21 & 0.99 & 1.49 \\
\hline
\end{tabular}

The sensitivity was $81 \%$, and the specificity was $80.4 \%$ when the optimum cut-off value of ADC was taken as $1.41 \times 10^{-3} \mathrm{~mm}^{2} / \mathrm{s}$ to differentiate between clinical stage I and other stages (II, III, and IV) (AUC:0.910; 
95CI:0.855-0.964; $p<0.001)$. The sensitivity was $93 \%$, and the specificity was $80.4 \%$ when the optimum cut-off value of ADC was similarly taken as $1.41 \times 10^{-3} \mathrm{~mm}^{2} / \mathrm{s}$ to distinguish between clinical stages I and more advanced stages (III and IV). (AUC: 0.964; 95CI:0.927-1.000; $p<0.001)$. The sensitivity was $100 \%$, and the specificity was $98.1 \%$ when the optimum threshold value of the ADC was taken as $1.22 \times 10^{-3} \mathrm{~mm}^{2} / \mathrm{s}$ to distinguish between clinical stage $I$ and stage IV(AUC:0.998; 95CI:0.994-1.000; $p<0.001$ ) (Figure 3).

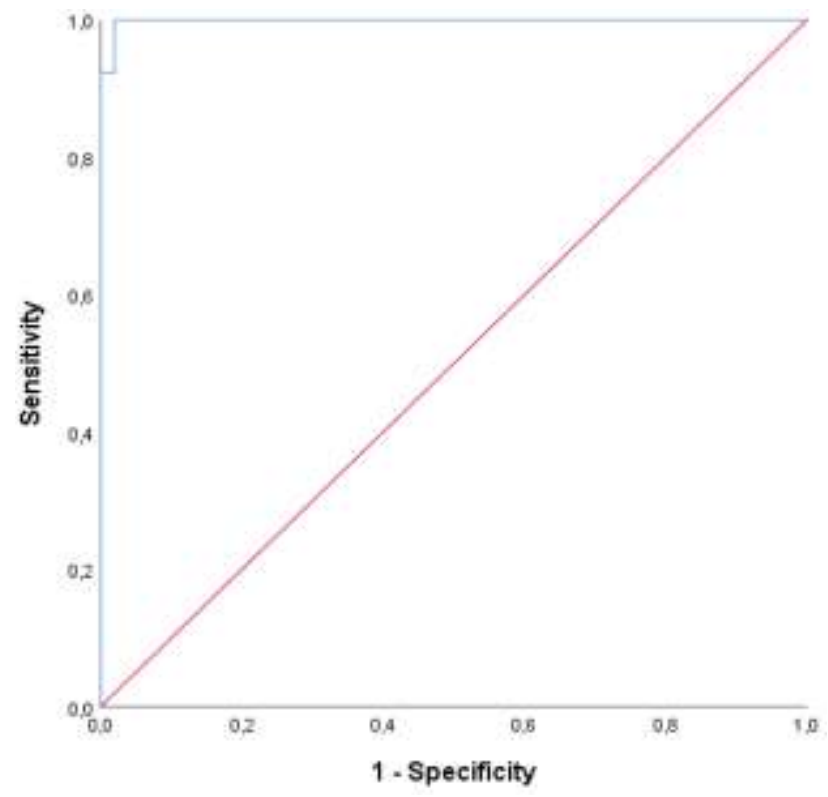

Figure 3. ROC curve showing success in discrimination between clinical stage I and stage IV of clear-cell RCC for and ADC $\leq 1.22 \times 10 \times 10^{-3}$ $\mathrm{mm}^{2} / \mathrm{s}$.

The mean ADC value for Fuhrman Grade I was $1.76 \pm 0.68 \times 10^{-3} \mathrm{~mm}^{2} / \mathrm{s}, 1.40 \pm 0.24 \times 10^{-3} \mathrm{~mm}^{2} / \mathrm{s}$ for grade $\geq \mathrm{II}, 1.17 \pm 0.16 \times 10^{-3} \mathrm{~mm}^{2} / \mathrm{s}$ for grade $\geq$ III and $1.19 \pm 0.21 \times 10^{-3} \mathrm{~mm}^{2} / \mathrm{s}$ for grade IV. Grade I had significantly higher ADC values than all groups $(\mathrm{p}<0.001)$. When the optimum cut-off value of ADC was taken as $1.67 \times 10^{-3}$ $\mathrm{mm}^{2} / \mathrm{s}$ to differentiate between Fuhrman grade I and other grades (II, III, and IV), the sensitivity was $88.2 \%$, and the specificity was
100\% (AUC: 0.927; 95CI: 0.872- 0.983; $p<0.001)$. When the optimum cut-off value of ADC was taken as $1.59 \times 10^{-3} \mathrm{~mm}^{2} / \mathrm{s}$ to differentiate between Fuhrman grade I and more advanced grades (II, III and IV), the sensitivity was $100 \%$, and the specificity was $100 \%$ (AUC:1.000; 95CI:1.000-1.000; $p<0.001)$ ) The sensitivity was $100 \%$, and the specificity was $100 \%$ when the optimum cutoff value of $\mathrm{ADC}$ was taken as $1.59 \times 10^{-3}$ $\mathrm{mm}^{2} / \mathrm{s}$ to differentiate between grade $\mathrm{I}$ and grade IV (AUC:1.000; 95CI:1.000-1.000; $p=0.001)$.

\section{Discussion}

The stage of RCC is based on the tumor diameter and extent of the invasion, which is defined in the AJCC Cancer Staging guidelines as follows: T1a tumor is $\leq 4 \mathrm{~cm}$ in greatest dimension and limited to the kidney; $\mathrm{T} 1 \mathrm{~b}$ tumor is between $4 \mathrm{~cm}$ and $7 \mathrm{~cm}$; T2a tumor is $>7 \mathrm{~cm}$ but $\leq 10 \mathrm{~cm}$ in size and limited to the kidney; $\mathrm{T} 2 \mathrm{~b}$ tumor is $>10 \mathrm{~cm}$ in size but confined within the kidney; T3 tumor extends into major veins or invades adrenal gland or perinephric tissues, but not beyond Gerota's fascia; and T4 tumor invades beyond Gerota's fascia (includes a contiguous extension into ipsilateral adrenal gland) [21, 22].

In the management of patients with RCC, minimally invasive ablative treatments can be used in stage I disease without lymph node or distant metastatic lesions, which may sometimes be challenging to detect on imaging studies, especially when they are small. Therefore, imaging parameters that can be used in the preoperative estimation of the clinical stage, which is one of the main parameters of the prognostic evaluation together with the pathological grade, have critical importance in guiding optimal management of the patients, particularly in the accurate differentiation of 
stage I clear cell RCC from advanced disease. Although studies performed to estimate the role of ADC in this differentiation are limited in number, they are suggestive of its potential utility as a quantitative method in preoperative clinical staging $[18,23]$. In this regard, we tried to determine the association of ADC values of clear cell RCC with every clinical stage on $3 \mathrm{~T}$ MR imaging.

Our study revealed that when the cut-off value of $\mathrm{ADC}$ is taken as $1.41 \times 10^{-3} \mathrm{~mm}^{2} / \mathrm{s}$, the sensitivity is $90 \%$ and the specificity is $80.4 \%$ to differentiate between clinical stage I and more advanced stages (III and IV) and when it is taken as $1.22 \times 10^{-3} \mathrm{~mm}^{2} / \mathrm{s}$ the sensitivity is $100 \%$. The specificity is $98.1 \%$ to differentiate between clinical stage I and stage IV. Previously, Nakamura et al. evaluated 49 patients with pathologically proven RCCs to compare the ADC values between each clinical stage and reported statistically significant differences in ADC values between stage 1 and more advanced stages (III and IV) [18]. In the study of Yoshida et al., 51 patients with 51 pathologically confirmed clear-cell RCCs who underwent $1.5 \mathrm{~T}$ MR imaging were retrospectively evaluated. A statistically significant difference in ADC values was reported between stages I clear-cell RCC and more advanced stage clear-cell RCCs with lymph node metastasis or distant metastasis. They found a sensitivity of $80.0 \%$ and a specificity of $81.0 \%$ for the optimal cut-off ADC value of $1.552 \times 10^{-3} \mathrm{~mm}^{2} / \mathrm{s}$ [23].

In addition to clinical staging, the nuclear grade of clear cell RCC also correlates with survival, particularly the Furhman grade [20, 24-26]. Previous studies reported a significant difference between ADC values of high grade and low-grade clear cell RCCs, particularly Furhman grades [18, 27-28]. In our study, we also tried to compare the ADC values for each
Furhman grade. Our study population was composed mainly of Furhman grade 2 clear cell RCCs. Similarly, in the study of Gürsoy et al., more than half of the patients were Fuhrman grade 2 with the rate of $61 \%$ among all four grades [29]. We found that Furhman grade I clear cell RCCs had significantly higher mean ADC values than all groups. The cut-off ADC value of $1.59 \times 10^{-3} \mathrm{~mm}^{2} / \mathrm{s}$ in our study was found to differentiate between Fuhrman grade I and advanced grades with sensitivity and specificity of $100 \%$. In one study, ADC values at b-value of $500 \mathrm{~s} / \mathrm{mm} 2$ were found to be significantly lower in Fuhrman grade III-IV clear cell RCC cases compared with Fuhrman grade I-II group, while no significant difference was found the difference was found between the groups at $b$ value of $1000 \mathrm{~s} / \mathrm{mm} 2$. The authors concluded that this could be explained to some extent by the explicitness of the perfusion effect at lower b values [9].

In a meta-analysis regarding the relationship between $b$ value and the detectability of RCC, standard b-value (800-1000 s/mm2) showed a superior specificity but an approximately equivalent sensitivity to low b-value (400-500 $\mathrm{s} / \mathrm{mm} 2$ ), which had an overall superior diagnostic accuracy [30]. The $b$ value we preferred in our study was 50 and $800 \mathrm{~s} / \mathrm{mm} 2$. The limitations of our study included the following; first, this was a single-center and a retrospective study. Second, evaluations were performed by only one single observer. Third, only two b-values (50 and $800 \mathrm{~mm} 2 / \mathrm{s}$ ) were used to calculate the ADC. Fourth, the reproducibility of the ADC values were not assessed. On the other hand, when compared with the present studies, our study stands out with its following features; we evaluated a relatively larger number of patients, we performed the MR imaging on 3T MR device, and ADC values were detailed for every clinical 
stage. Moreover, the ADC values were also compared for each Furhman grade.

\section{Conclusion}

In conclusion, we assessed the utility of ADC in a relatively large number of patients with clear cell RCC for differentiating preoperative clinical stages and Furhman grades. We found a statistically significant difference in ADC values between early-stage clear cell RCC and advanced stages of the disease. In patients with kidney masses suggestive of clear cell RCC on imaging studies, the ADC of primary tumor site less than $1.41 \times 10^{-3} \mathrm{~mm}^{2} / \mathrm{s}$ should be considered for the possibility of lymph node or distant metastatic lesions, and the values less than 1.22 $\times 10^{-3} \mathrm{~mm}^{2} / \mathrm{s}$ should be strongly suggested for distant metastasis. The accurate preoperative characterization of clear cell RCC is essential to ensure appropriate clinical management of patients and contributes to the prognosis. Therefore, the ADC value of the primary tumor site should be evaluated in predicting the clinical stage of clear cell RCC.

Funding: The author(s) received no financial support for the research, authorship, and/or publication of this article.

Conflict of Interest: The authors declare that they have no conflict of interest.

Ethical statement: The study was approved by the Recep Tayyip Erdoğan University Faculty of Medicine Clinical Research Ethics Committee (Date: 2021-11-11/No: 2021/195).

\section{Open Access Statement}

This is an open access journal which means that all content is freely available without charge to the user or his/her institution under the terms of the Creative Commons Attribution NonCommercial License (https://creativecommons.org/licenses/by/4.0/). Users are allowed to read, download, copy, distribute, print, search, or link to the full texts of the articles, without asking prior permission from the publisher or the author.

Copyright (c) 2021: Author (s).

\section{References}

[1]NG CS, Wood CG, Silverman PM, et al. Renal cell carcinoma: diagnosis, staging, and surveillance. Am J Roentgenol. 2008;191(4):1220-32.

[2]Siegel RL, Miller KD, Jemal A. Cancer statistics, 2018. CA Cancer J Clin. 2018;68(1):7-30.

[3]Federle MP, Jeffrey RB, Woodward PJ, et al. Diagnostic Imaging: Abdomen. Lippincott Williams \& Wilkins, Amirsys; 2009. P.2-02.

[4]Hsieh JJ, Purdue MP, Signoretti S, et al. Renal cell carcinoma. Nat Rev Dis Primers. 2017;9(3):17009.

[5]Graham TM, Stevens TM, Gordetsky JB. Pathology of renal tumors. In Diagnosis and surgical management of renal tumors. Springer, Cham; 2019. p. 13-38.

[6]Escudier B, Porta C, Schmidinger M, et al. Renal cell carcinoma: ESMO Clinical Practice Guidelines for diagnosis, treatment and follow-up. Ann Oncol. 2016;27 (suppl 5):58-68.

[7]Beck SD, Patel MI, Snyder ME, et al. Effect of papillary and chromophobe cell type on disease-free survival after nephrectomy for renal cell carcinoma. Ann Surg Oncol. 2004;11(1):71-77.

[8]Cheville JC, Lohse CM, Zincke H, et al. Comparisons of outcome and prognostic features among histologic subtypes of renal cell carcinoma. Am J Surg Pathol. 2003;27(5):612-24.

[9]Kıs N, Erok B. Diffusion weighted imaging in differentiation of the clear cell RCC from the major non-clear cell RCC subtypes. Eur J Clin Exp Med. 2021;19(3):215-20. 
[10]Koh DM, Collins DJ. Diffusion-weighted MRI in the body: applications and challenges in oncology. Am J Roentgenol. 2007;188(6):1622-35.

[11]Elmi A, Hedgire SS, Covarrubias D, et al. Apparent diffusion coefficient as a noninvasive predictor of treatment response and recurrence in locally advanced rectal cancer. Clin Radiol. 2013;68(10):524-31.

[12] Arvinda HR, Kesavadas C, Sarma PS, et al. Glioma grading: sensitivity, specificity, positive and negative predictive values of diffusion and perfusion imaging. $\mathrm{J}$ Neurooncol. 2009;94(1):87-96.

[13] Tamada T, Sone T, Jo Y, et al. Apparent diffusion coefficient values in peripheral and transition zones of the prostate: comparison between normal and malignant prostatic tissues and correlation with histologic grade. J Magn Reson Imaging. 2008;28(3):720-26.

[14] Yılmaz E, Erok B, Atca AÖ. Measurement of apparent diffusion coefficient in discrimination of benign and malignant axillary lymph nodes. Pol J Radiol. 2019;84:592-97.

[15]Er HÇ, Peker E, Erden A, Öztürk E. The utility of diffusion-weighted imaging in differentiation of papillary and clear cell subtypes of renal cell carcinoma. Acta Oncol Tur. 2015;48(1):8-14.

[16] Yu X, Lin M, Ouyang H, et al. Application of ADC measurement in characterization of renal cell carcinomas with different pathological types and grades by 3.0T diffusion-weighted MRI. Eur J Radiol. 2012;81(11):3061-66.

[17] Maruyama M, Yoshizako T, Uchida K, et al. Comparison of utility of tumor size and apparent diffusion coefficient for differentiation of low- and high-grade clearcell renal cell carcinoma. Acta Radiol. 2015;56(2):250-56.
[18] Nakamura T, Yoshizako T, Araki H, et al. The relation between apparent diffusion coefficient and clinical stage of clear-cell renal cell carcinoma. Clin imaging. 2015;39(1):72-75.

[19]Edge SB, Byrd DR, Compton CC, et al. AJCC Cancer Staging Manual. 7th ed. New York: Springer; 2010.

[20]Fuhrman SA, Lasky LC, Limas C. Prognostic significance of morphologic parameters in renal cell carcinoma. Am J Surg Pathol. 1982;6(7):655-63.

[21] Motzer RJ, Jonasch E, Agarwal N, et al. Kidney cancer, version 3. J Natl Compr Canc Netw. 2015;13(2):151-59.

[22] Swami U, Nussenzveig RH, Haaland B, Agarwal N. Revisiting AJCC TNM staging for renal cell carcinoma: quest for improvement. Ann Transl Med. 2019;7(Suppl 1):S18.

[23]Rika Yoshida, Takeshi Yoshizako, Araki Hisatoshi, et al. The additional utility of apparent diffusion coefficient values of clear-cell renal cell carcinoma for predicting metastasis during clinical staging. Acta Radiol Open. 2017;6(1):2058460116687174.

[24]Delahunt B. Advances and controversies in grading and staging of renal cell carcinoma. Mod Pathol. 2009;22(Suppl 2):24-36.

[25] Medeiros LJ, Jones EC, Aizawa S, et al. Grading of renal cell carcinoma: Workgroup No. 2. Union Internationale Contre le Cancer and the American Joint Committee on Cancer (AJCC). Cancer. 1997;80(5):990-91. [26] Delahunt B, Cheville JC, Martignoni G, et al. The International Society of Urological Pathology (ISUP) grading system for renal cell carcinoma and other prognostic parameters. Am J Surg Pathol. 2013;37(10):1490-504. 
[27] Goyal A, Sharma R, Bhalla AS, et al. Diffusion-weighted MRI in renal cell carcinoma: a surrogate marker for predicting nuclear grade and histological subtype. Acta Radiol. 2012;53(3):349-58.

[28] Paudyal B, Paudyal P, Tsushima Y, et al. The role of the ADC value in the characterisation of renal carcinoma by diffusion-weighted MRI. $\mathrm{Br} \mathrm{J}$ Radiol. 2010;83(988):336-43.

[29] Gürsoy D, Seçinti İ.E., Hakverdi S., Görür S. Renal Cell Carcinoma: Epidemiological Profile and Histopathological Features. Bulletin of Urooncology. 2020;19(2):68-73.

[30]Tang Y, Zhou Y, Du W, et al. Standard bvalue versus low $b$-value diffusion-weighted MRI in renal cell carcinoma: a systematic review and meta-analysis. BMC Cancer. 2014;14:843. 